\title{
GM-CSF increases LPS-induced production of proinflammatory mediators via upregulation of TLR4 and CD14 in murine microglia
}

Bijay Parajuli ${ }^{1}$, Yoshifumi Sonobe ${ }^{1 *}$, Jun Kawanokuchi ${ }^{1}$, Yukiko Doi $^{1}$, Mariko Noda ${ }^{1,2}$, Hideyuki Takeuchi ${ }^{1}$, Tetsuya Mizuno ${ }^{1}$ and Akio Suzumura ${ }^{1}$

\begin{abstract}
Background: Microglia are resident macrophage-like cells in the central nervous system (CNS) and cause innate immune responses via the LPS receptors, Toll-like receptor (TLR) 4 and CD14, in a variety of neuroinflammatory disorders including bacterial infection, Alzheimer's disease, and amyotrophic lateral sclerosis. Granulocyte macrophage-colony stimulating factor (GM-CSF) activates microglia and induces inflammatory responses via binding to GM-CSF receptor complex composed of two different subunit GM-CSF receptor a (GM-CSFRa) and common $\beta$ chain ( $\beta c)$. GM-CSF has been shown to be associated with neuroinflammatory responses in multiple sclerosis and Alzheimer's disease. However, the mechanisms how GM-CSF promotes neuroinflammation still remain unclear.
\end{abstract}

Methods: Microglia were stimulated with $20 \mathrm{ng} / \mathrm{ml} \mathrm{GM-CSF}$ and the levels of TLR4 and CD14 expression were evaluated by RT-PCR and flowcytometry. LPS binding was analyzed by flowcytometry. GM-CSF receptor complex was analyzed by immunocytechemistry. The levels of IL-1 $\beta$, IL-6 and TNF-a in culture supernatant of GM-CSF-stimulated microglia and NF-KB nuclear translocation were determined by ELISA. Production of nitric oxide (NO) was measured by the Griess method. The levels of p-ERK1/2, ERK1/2, p-p38 and p38 were assessed by Western blotting. Statistically significant differences between experimental groups were determined by one-way ANOVA followed by Tukey test for multiple comparisons.

Results: GM-CSF receptor complex was expressed in microglia. GM-CSF enhanced TLR4 and CD14 expressions in microglia and subsequent LPS-binding to the cell surface. In addition, GM-CSF priming increased LPS-induced NF-KB nuclear translocation and production of IL-1 $\beta, I L-6$, TNF- $a$ and NO by microglia. GM-CSF upregulated the levels of p-ERK1/2 and p-p38, suggesting that induction of TLR4 and CD14 expression by GM-CSF was mediated through ERK $1 / 2$ and p38, respectively.

Conclusions: These results suggest that GM-CSF upregulates TLR4 and CD14 expression in microglia through ERK1/2 and p38, respectively, and thus promotes the LPS receptor-mediated inflammation in the CNS.

Keywords: Microglia, TLR4, CD14, GM-CSF, NF-KB

\footnotetext{
* Correspondence: sonobe@riem.nagoya-u.ac.jp

'Department of Neuroimmunology, Research Institute of Environmental Medicine, Nagoya University, Furo-cho, Chikusa-ku, Nagoya 464-8601, Japan Full list of author information is available at the end of the article
} 


\section{Background}

Microglia are resident macrophage-like cells in the central nervous system (CNS). They become activated in response to bacterial infection including gram-negative bacteria, Candida albicans, and Cryptococcus neoformans, and initiate an inflammatory response [1,2]. The principal mechanism that initiates microglial response may be the toll-like receptor (TLR) family of receptors $[1,2]$. TLRs serve as pathogen-associated molecular pattern recognition receptors that bind microbial molecular motif with high affinity, and play a central role in the initiation of cellular innate immune responses [3]. TLR4 and CD14 are constitutively expressed in microglia $[1,4]$ and their ligand, lipopolysaccharide (LPS) induces production of inflammatory mediators including TNF- $\alpha$, IL-6, and nitric oxide $(\mathrm{NO})[4,5]$, via the nuclear factor $\kappa \mathrm{B}(\mathrm{NF}-\mathrm{\kappa B})$ signaling pathway [6].

It is reported that TLR4 on microglia recognizes fibrillar $A \beta$ [7]. Activation of TLR4 is reported to be associated with increased production of TNF- $\alpha$ and IL- $1 \beta$ in the CNS of APPswe/PS1 transgenic mice, a mouse model of Alzheimer's disease (AD) [8]. Genetic deficiency in CD14 reduces $A \beta$-induced microglial $\mathrm{NO}$ and IL-6 production [9], and Alzheimer pathology in APPswe/PS1 transgenic mice [10], suggesting that the LPS receptor plays an important role in inflammation in $\mathrm{AD}$. Furthermore, human mutations in $(\mathrm{Cu} / \mathrm{Zn})$ superoxide dismutase-1 (mSOD1) G93A and G85R, which cause non-cell-autonomous motor neuron death in amyotrophic lateral sclerosis (ALS), activate microglia and induce production of inflammatory mediators, including TNF- $\alpha$, IL-1 $\beta$, and NO [11]. TLR4 expression in microglia is reportedly increased in the spinal cord of ALS patients [12]. Thus, these findings suggest that the LPS receptor plays an important role, not only in pathogen-induced inflammation, but also in inflammation caused by misfolded protein, like fibrillar $\mathrm{A} \beta$ and $\mathrm{mSOD} 1$ in neurodegenerative diseases.

Granulocyte macrophage colony-stimulating factor (GM-CSF) is a pleiotropic cytokine secreted by a wide variety of cells including endothelial cells, monocytes, astrocytes, and T cells [13-17]. GM-CSF exerts its biological function by binding to GM-CSF receptor complex composed of two different subunits of GM-CSF receptor alpha (GM-CSFR $\alpha$ ) which shows ligand-specific binding, and a common $\beta(\beta c)$ subunit, which is shared with closely associated cytokines IL- 3 and IL-5, and acts as the signal transduction chain $[18,19]$. GM-CSF signal is transmitted through Janus kinase (JAK) 2, mitogen activated protein kinase (MAPK) and phosphatidylinositol 3-kinase (PI3K) [20-22].

GM-CSF has been shown to be upregulated in various neurological disorders like $\mathrm{AD}$, vascular dementia, multiple sclerosis (MS) [23,24]. Indeed, GM-CSF-deficient mice are reportedly resistant to experimental autoimmune encephalomyelitis, an animal model of MS [16,17], in which microglial activation is reduced. Moreover, neutralization of GM-CSF by antibodies suppresses microglial activation in the cerebral cortices of the mouse model of AD, Tg2576 mice [25]. Thus, it is expected that GM-CSF is associated with promoting CNS inflammation via microglial activation. We previously reported that GM-CSF was able to induce phagocytosis, proliferation, IL-6 production, and MHC class II expression in microglia $[26,27]$. However, GM-CSF by itself failed to induce some proinflammatory mediators such as TNF- $\alpha$ and NO, suggesting that GM-CSF might promote inflammation in the CNS via activating microglia both directly and indirectly. However, the mechanisms by which GM-CSF enhances such a broad neuroinflammatory response are still far from clear.

Here, we show that the GM-CSF receptor complex, GM-CSFR $\alpha$ and GM-CSFR $\beta$, is strongly expressed in microglia. GM-CSF enhances TLR4 and CD14 expression in microglia, leading to increase of LPS-induced NF- $\mathrm{kB}$ nuclear translocation and increased LPS-mediated IL-6, TNF- $\alpha$, and NO production. GM-CSF-induced expression of TLR4 and CD14 was mediated through ERK1/2 and $\mathrm{p} 38$, respectively. These results suggest that GM-CSF promotes the LPS receptor-mediated neuroinflammation via upregulating TLR4 and CD14 expression in microglia.

\section{Material and methods Reagents}

Recombinant mouse GM-CSF was obtained from R\&D systems (Minneapolis, MN, USA). LPS was obtained from Sigma-Aldrich (St Louis, MO, USA). Wortmannin (PI3K inhibitor), U0126 (MEK1/2 inhibitor), SB203580 (p38 inhibitor), SP600125 (c-Jun N-terminal kinase (JNK) inhibitor), and NF-kB inhibitor SN50 were obtained from Calbiochem (Gibbstown, NJ, USA). Anti-phospho-p44/ 42 MAPK (p-ERK1/2), anti-p42/44 MAPK antibodies (extracellular signal-regulated kinase 1/2: ERK1/2), antiphospho-p38 and anti-p38 were obtained from Cell Signaling Technology (Danvers, MA, USA). The other antibodies used were as follows: anti-TLR4 (eBioscience, San Diego, CA, USA), anti-CD14 (BioLegend, San Diego, CA, USA), anti-CD11b (Serotec, Kidlington, UK), antiGFAP (Dako, Glostrup, Denmark), anti-Iba1 (Wako, Osaka, Japan), anti-MAP2 (Merck Millipore, Billerica, MA, USA), anti-GM-CSFR $\alpha$ (R\&D systems, Minneapolis, MN, USA), and anti-NeuN (Merck Millipore).

\section{Cell culture}

All animal experiments were conducted under protocols that were approved by the Animal Experiment Committee of Nagoya University. All primary cultures were prepared from C57BL/6 mice (Japan SLC, Hamamatsu, Japan). 
Microglia were isolated from primary mixed glial cell cultures prepared from newborn mice on day 14 using the shaking-off method as previously described [27]. The purity of the cultures (> 99\%) was determined by anti-CD11b immunostaining. The cultures were maintained in Dulbecco's modified Eagle's minimum essential medium (Sigma-Aldrich) supplemented with 10\% fetal bovine serum (SAFC Biosciences, Lenexa, $\mathrm{KS}$, USA), $5 \mu \mathrm{g} / \mathrm{ml}$ bovine insulin (Sigma-Aldrich), and $0.2 \%$ glucose.

Primary neuronal cultures were prepared from the cortices of embryos at embryonic day 17 (E17) as described previously [28]. Briefly, cortical fragments were dissociated into single cells in dissociation solution (Sumitomo Bakelite, Akita, Japan) and resuspended in nerve culture medium (Sumitomo Bakelite). Neurons were seeded onto 12-mm polyethyleneimine-(PEI)-coated glass cover slips (Asahi Techno Glass Corp, Chiba, Japan) at a density of $5 \times 104$ cells/well in 24-well plates. The purity of the culture was more than $95 \%$ as determined by NeuN-specific immunostaining.

Primary astrocytes were isolated as previously described [29]. Briefly, microglial cells were removed from mixed glial cell cultures from newborn mice and the remaining cultures were trypsinized and re-plated in tissue culture plates. Cultures after three passages were used as astrocytes. The purity of the culture was more than $95 \%$ as determined by glial fibrillary acidic protein (GFAP)specific immunostaining.

\section{Reverse transcription (RT)-PCR}

For quantitative PCR, microglia were treated with GM-CSF $(20 \mathrm{ng} / \mathrm{ml})$ for varying times (6 to $72 \mathrm{~h}$ ). Similarly, microglia were treated with GM-CSF $(20 \mathrm{ng} / \mathrm{ml})$ for $48 \mathrm{~h}$ or left untreated in RepCell ${ }^{\circledR}$ (CellSeed, London, UK), in which cells are adherent at $37^{\circ} \mathrm{C}$ but detach from the plate at 20 to $25^{\circ} \mathrm{C}$. Then the cells were harvested, washed twice and seeded on 24-well plates at a density of $1 \times 10^{5}$ cells/well. After stimulation with varying concentrations of LPS for $48 \mathrm{~h}$, the total cellular RNA was extracted using the RNeasy Mini Kit (Qiagen, Hilden, Germany). cDNA was synthesized from total cellular RNA that was denatured for 5 minutes at $65^{\circ} \mathrm{C}$, followed by reverse transcription reaction using the SuperScript II (Life Technologies, Carlsbad, CA, USA). The cDNA served as a template to amplify genes in RT-PCRs with TaqMan Gene Expression assays (Applied Biosystems), Universal PCR Master Mix (Applied Biosystems), and Rotor-Gene Q (Qiagen). Expression levels of target genes were calculated using a comparative method and normalized to GAPDH expression levels as previously described [30]. The following primers and probes were obtained from Applied Biosystems: IL-1 $\beta$, Mm00434228_m1; IL-6, Mm00446190_m1; TNF- $\alpha$, Mm00443258_m1; GAPDH, Mm99999915_g1;
NOS2, Mm00440502_m1; CD14, Mm00438094_m1; and TLR4, Mm00445273_m1.

For semi-quantitative PCR, the total cellular RNA from astrocytes, neurons and microglia were extracted using the RNeasy Mini Kit (Qiagen). cDNA was synthesized from total cellular RNA as described above with SuperScript II (Life Technologies) and semiquantitative PCR was performed using Ampli Taq DNA polymerase (Applied Biosystems) as previously described [31] using the following the specific primer sets: GAPDH GAPDH sense, 5'-ACTCACGGGAAATTCA ACG-3'; GAPDH antisense, 5'-CCCTGTTGCTGTAGCCG TA-3'; GM-CSFR $\alpha$ sense, 5'-TGGCGAACGACTTGTCA CTGCT-3'; GM-CSFR $\alpha$ antisense, 5'-GCACCTTGA CCTTGTGACCT- $3^{\prime}$; GM-CSFR $\beta$ sense, $5^{\prime}$-TGTTCCA GGATGGAGGTAAA- $3^{\prime}$; GM-CSFR $\beta$ an-tisense, $5^{\prime}-\mathrm{C}$ CCACACTGCACATCCATAG-3'.

\section{Flow cytometry (FCM)}

FCM was done as previously described [26]. Briefly, microglia cells treated with GM-CSF or left untreated were blocked with Fc block for 30 minutes in fluorescenceactivated cell sorter (FACS) buffer and then cells were stained with phycoerythrin (PE)-conjugated-anti-TLR4, PEconjugated-anti-CD14, or isotype-matched control. The cells were subsequently analyzed using a Cytomics FC500 (Beckman Coulter, Brea, CA, USA). To assess LPS binding, microglia cultured in the presence or absence of GM-CSF for $48 \mathrm{~h}$, were treated with Alexa 488-conjugated LPS for $1 \mathrm{~h}$. After washing twice to remove any unbound LPS, cells were analyzed using a Cytomics FC500.

\section{Immunocytochemistry}

Immunocytochemistry was done as previously described [32]. Microglia, astrocytes or neurons plated on glass cover slips were fixed with $4 \%$ paraformaldehyde for 10 minutes, cells were then permeabilized with $0.05 \%$ Triton X-100 for 5 minutes and blocked with 5\% goat serum for $1 \mathrm{~h}$, followed by incubation with anti-iba1, anti-GFAP, or anti-MAP2 and GM-CSFR $\alpha$, antibodies overnight at $4^{\circ} \mathrm{C}$. Then, the cells were incubated with Alexa 488- or Alexa 568-conjugated secondary antibodies for $1 \mathrm{~h}$. Cells were examined with a deconvolution fluorescence microscope system (Bio Zero, Keyence, Osaka, Japan).

\section{Measurement of $\mathrm{NO}$ and cytokines}

Microglia were treated with GM-CSF for $48 \mathrm{~h}$ or left untreated in RepCell. Then the cells were harvested, washed twice and seeded at a density of $1 \times 10^{5}$ cells/ well in 24 well plates. Then the cells were treated with varying concentrations of LPS $(0.01$ to $1 \mu \mathrm{g} / \mathrm{ml})$ for $48 \mathrm{~h}$. Supernatants were collected and NO production was determined by the Griess reaction as previously described [31]. The levels of IL-1 $\beta$ IL- 6 and TNF- $\alpha$ in culture supernatant 
were determined by ELISA according to the manufacturer's instructions (BD Biosciences).

\section{NF-KB nuclear translocation}

Microglia primed with GM-CSF for $48 \mathrm{~h}$ or left untreated were seeded on 6-well plates at $1 \times 10^{7}$ cells/well and treated with LPS $(1 \mu \mathrm{g} / \mathrm{ml})$ for 0 to 30 minutes. Nuclear fractions from the cells were separated and the levels of NF- $\mathrm{kB}$ in the nuclear fractions were analyzed using the NF- $\mathrm{kB} /$ p65-active ELISA kit (Imgenex, San Diego, CA, USA) according to the manufacturer's instructions.

\section{Western blotting}

Microglia were treated with GM-CSF (20 ng/ml) for varying times (15 to 120 minutes). After washing with
PBS, cells were lysed with TNES buffer (1 M Tris-HCl, $20 \%$ SDS and $2.5 \%$ glycerol) containing phosphatase (Sigma-Aldrich) and protease inhibitor (Roche, Mannheim, Germany); $50 \mu \mathrm{g}$ of protein from the total lysate was assayed for phosphorylated ERK1/2, phosphorylated p38, total ERK and total p38 by western blotting as described previously [31].

\section{Statistical analysis}

Statistically significant differences between experimental groups were determined by one-way analysis of variance (ANOVA) followed by Tukey test for multiple comparisons. Statistical analysis was performed using the software program Prism 4.0 (GraphPad Software, San Diego,

A

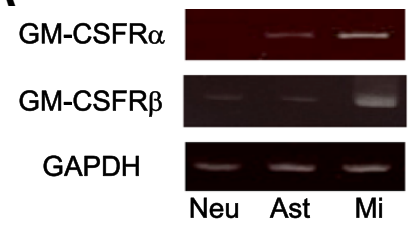

B

$\alpha-M A P 2$

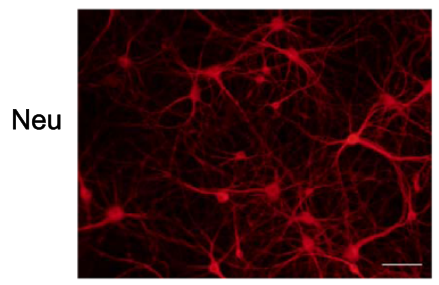

$\alpha$-GFAP

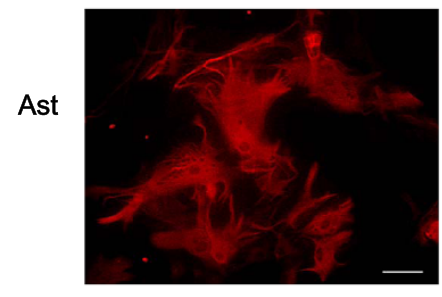

$\alpha-$-lba 1

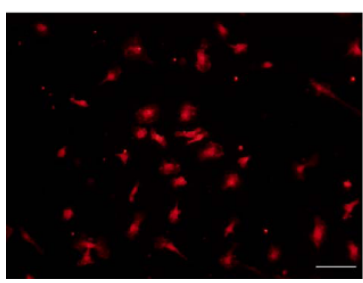

$\alpha-G M-C S F R \alpha$

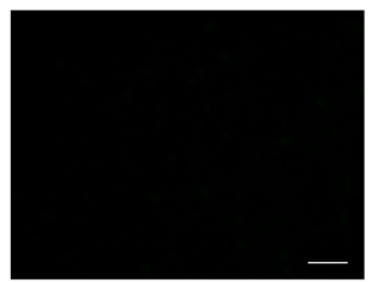

$\alpha-G M-C S F R \alpha$

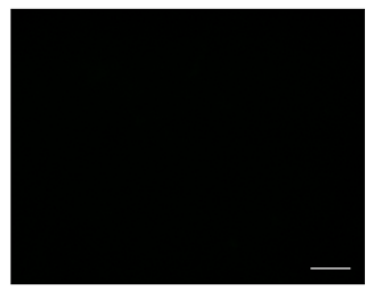

$\alpha-G M-C S F R \alpha$

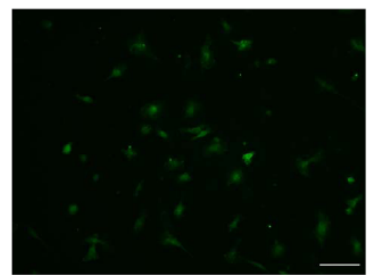

Merge

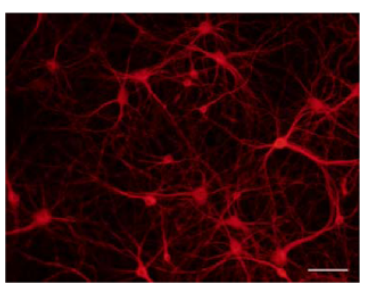

Merge

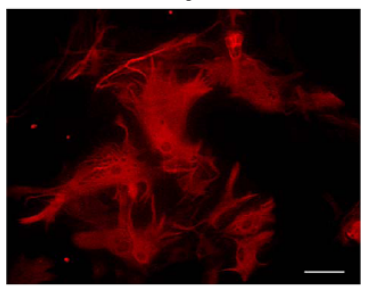

Merge

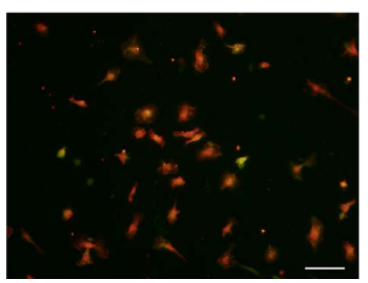

Figure 1 Granulocyte macrophage-colony stimulating factor (GM-CSF) receptor complex is predominantly expressed in microglia in the central nervous system (CNS). (A) The expression levels of GM-CSF Ra and GM-CSF R 3 mRNA in neurons, astrocytes, and microglia were analyzed by semi-quantitative PCR. (B) Surface expression of GM-CSF Ra in neurons, astrocytes and microglia was analyzed by immunocytochemistry. Data are representative of three independent experiments. Scale bar represents 50 um. 

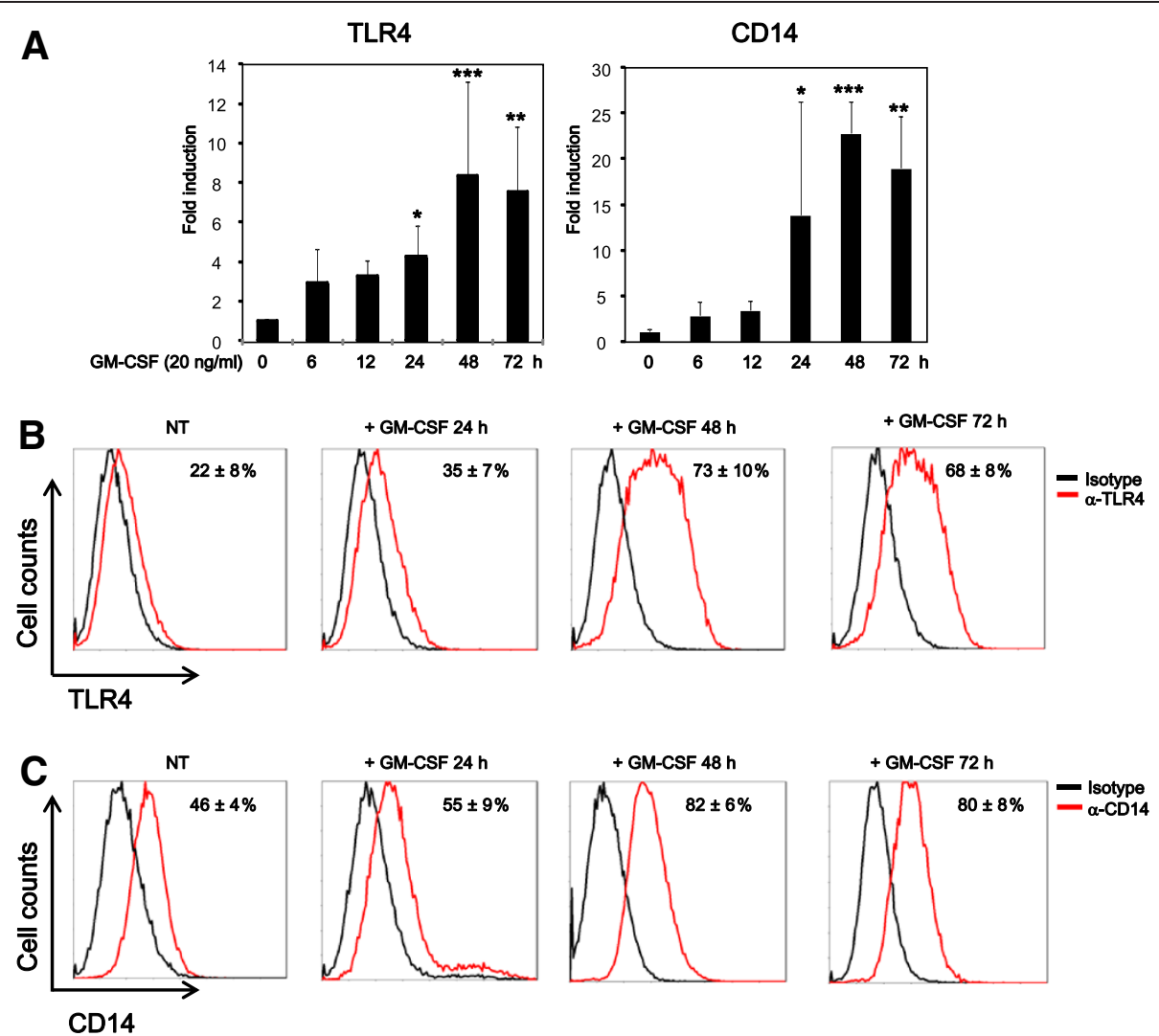

Figure 2 Granulocyte macrophage-colony stimulating factor (GM-CSF) increases toll-like receptor (TLR) 4 and CD14 expression in microglia. (A) Microglia were treated with GM-CSF $(20 \mathrm{ng} / \mathrm{ml})$ for 6 to $72 \mathrm{~h}$ and analyzed for expression of TLR4 and CD14 mRNA by real-time PCR. (B, C) Microglia treated with GM-CSF at $20 \mathrm{ng} / \mathrm{ml}$ were analyzed for surface expression of TLR4 and CD14 by flow cytometry (FCM). Data indicate mean $\pm \mathrm{SD}$ of three independent experiments. ${ }^{*} P<0.05,{ }^{*} P<0.01,{ }^{* * *} P<0.001$ (GM-CSF-treated vs. -untreated).

CA, USA). P-values less than 0.05 were considered statistically significant.

\section{Results}

\section{GM-CSFR complex is expressed in microglia}

We first assessed the basal expression of GM-CSFR $\alpha$ and GM-CSFR $\beta$ mRNA in microglia, astrocytes and neurons. Microglia expressed both GM-CSFR $\alpha$ and GM-CSFR $\beta$ mRNA (Figure 1A). The expression of GM-CSFR $\alpha$ and GM-CSFR $\beta$ mRNA in astrocytes and GM-CSFR $\beta$ mRNA in neurons was very weak (Figure 1A). Immunocytochemistry confirmed that microglia, but not neurons and atrocytes, expressed GM-CSFR $\alpha$ protein (Figure 1B). These results indicate that functional GM-CSFR is expressed in microglia in the CNS.

\section{GM-CSF increases TLR4 and CD14 expression in microglia} We next assessed expression of the LPS receptor, TLR4, and CD14 in microglia. GM-CSF time-dependently increased expression of TLR4 and CD14 mRNA, which peaked at $48 \mathrm{~h}$ and remained stabilized until $72 \mathrm{~h}$ in microglia (Figure 2A). FCM also showed that GM-CSF upregulated the surface expression of TLR4 and CD14 in microglia, which peaked at $48 \mathrm{~h}$ and remained stabilized until $72 \mathrm{~h}$ (Figure 2B and C). To further confirm that GM-CSF increased the LPS receptor expression, we assessed binding of Alexa488-conjugated LPS in GM-

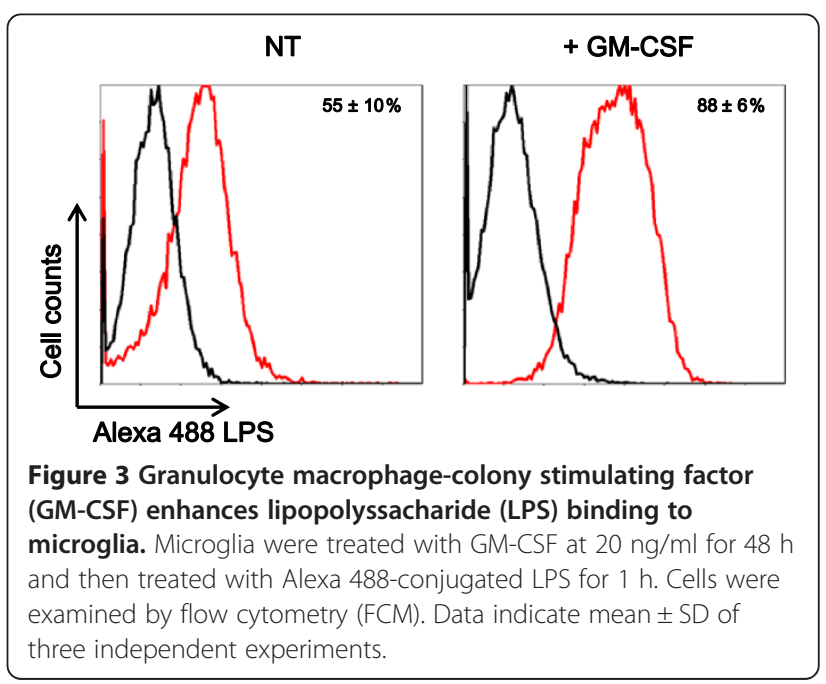



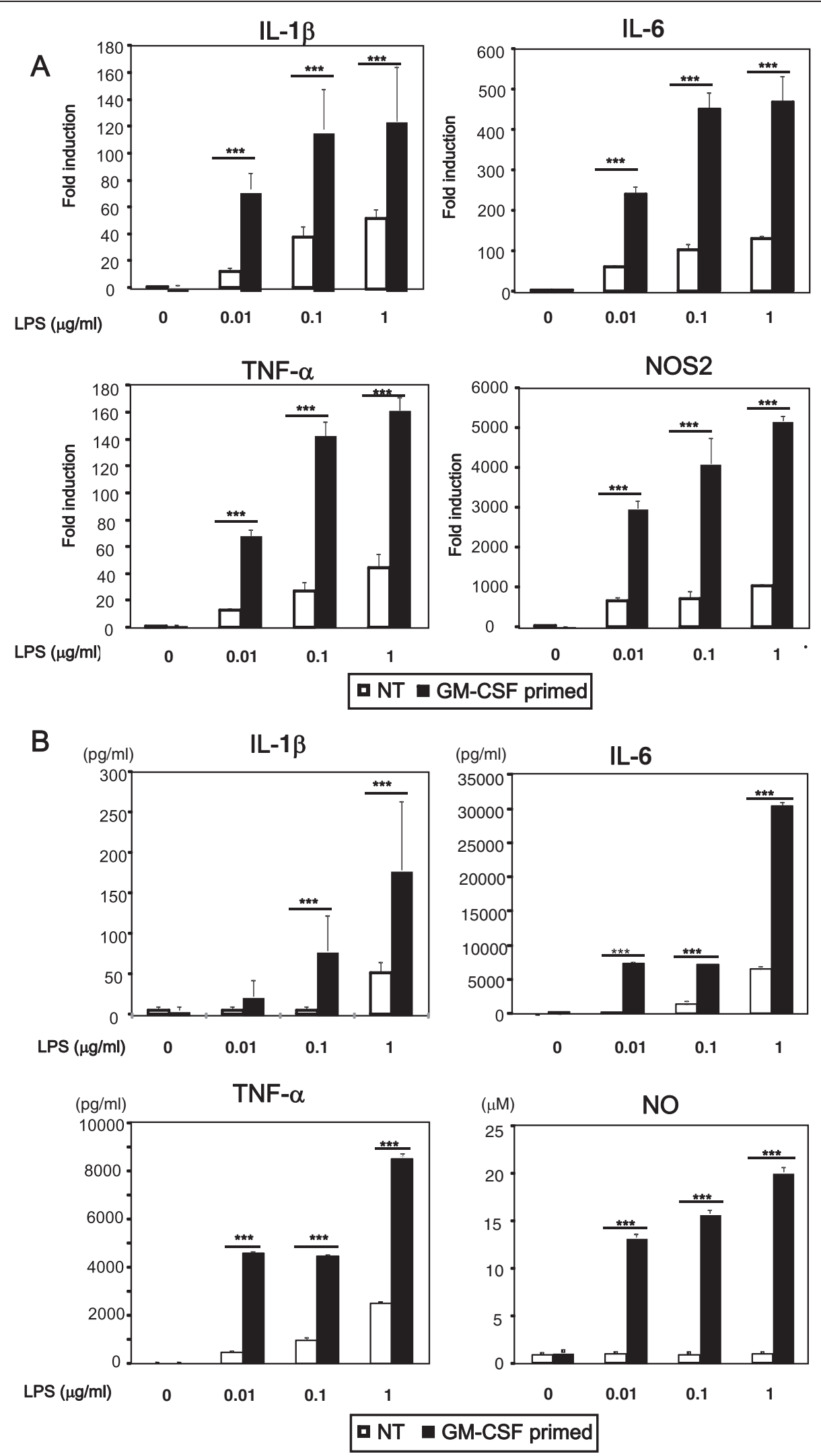

Figure 4 (See legend on next page). 
(See figure on previous page).

Figure 4 Granulocyte macrophage-colony stimulating factor (GM-CSF) increases lipopolysaccharide (LPS)-induced IL-6, nitric oxide (NO), and TNF-a production. After pretreating with GM-CSF or leaving untreated for $48 \mathrm{~h}$, microglia were harvested, washed twice, and seeded at $1 \times 10^{5}$ cells/well. Then the cells were treated with varying doses of LPS $(0.01$ to $1 \mu \mathrm{g} / \mathrm{ml})$ for $48 \mathrm{~h}$. (A) The expression levels of IL-1 $\beta$, IL-6, TNF$a$ and NOS2, mRNA were assessed by quantitative real-time PCR. (B) Concentrations of IL-1 $\beta, I L-6$, TNF- $a$, and NO in culture supernatant were analyzed by ELISA and the Griess method. Data indicate mean \pm SD. Data are representative of three independent experiments. ${ }^{* * *} P<0.001$ (GM-CSF pretreated vs. untreated).

CSF-primed and -unprimed microglia. GM-CSF priming increased the surface binding of LPS (Figure 3). These results indicate that GM-CSF increase expression of TLR4 and CD14 in microglia.

\section{GM-CSF enhances LPS-induced production of inflammatory mediators}

We then examined whether GM-CSF affects LPS-mediated function in microglia. We pretreated microglia with GM-CSF for $48 \mathrm{~h}$, then the cells were harvested, washed, seeded at a density of $1 \times 10^{5}$ cells/well in 24-well plates, and further stimulated with varying doses of LPS (0.01 to $1 \mu \mathrm{g} / \mathrm{ml})$ for $48 \mathrm{~h}$. GM-CSF priming increased LPS-induced expression of IL-1 $\beta$, IL- 6 , TNF- $\alpha$ and NOS 2 mRNA as compared to unprimed microglia (Figure 4A). Similarly, GM-CSF priming increased LPS-induced secretion of IL-1 $\beta$, IL-6, TNF- $\alpha$ and NO (Figure 4B).

NF- $\mathrm{KB}$ plays a critical role in the production of various proinflammatory molecules, including IL- 6 and TNF- $\alpha$, by activation of TLR4 [6]. To further characterize GM-CSF priming of LPS response, to find out whether increased TLR4 and CD14 are associated with enhanced nuclear translocation of NF-kB, we assessed nuclear translocation of NF-kB. GM-CSF priming significantly increased the levels of LPS-induced NF- $\mathrm{kB}$ nuclear translocation as compared to unprimed cells (Figure 5). To reveal the requirement of NF- $\mathrm{kB}$ in LPS-induced increased production of cytokines in GM-CSF-primed or -unprimed cells, we inhibited NF-kB signaling with SN50 before LPS stimulation, and assessed IL-1 $\beta$, IL-6, TNF- $\alpha$ and NO production by ELISA and Griess reagent, respectively. SN50 dose-dependently inhibited production of LPS-induced IL-1 $\beta$, IL-6, TNF- $\alpha$ and NO in both unprimed and GM-CSF-primed microglia, although a higher dose was required to completely inhibit the production of IL-1 $\beta$, IL-6, TNF- $\alpha$, and NO in GM-CSF-primed microglia (Figure 6). These results indicate that GM-CSF priming increases LPS-mediated production of IL- $1 \beta$, IL-6, TNF- $\alpha$ and NO via increasing activation of NF- $\mathrm{kB}$.

\section{GM-CSF-induced expression of TLR4 and CD14 is mediated via ERK1/2 and p38 activation, respectively}

GM-CSF has been shown to activate JAK2, PI3K, ERK1/2, and p38 in microglia [20-22]. We evaluated the pathway involved in GM-CSF-induced upregulation of TLR4 and CD14 expression in microglia. JAK2 inhibitor, PI3K inhibitor, Wortmannin, and NF-kB inhibitor, SN50 had no effect in GM-CSF-induced increase of TLR4 and CD14 expression. The MEK1/2 inhibitor, U0126 (1 $\mu \mathrm{M} / \mathrm{ml})$ suppressed GM-CSF-induced surface expression of TLR4 but did not reach basal level (Figure 7A). SB203580 had no effect in the surface expression TLR4. In contrast, the p38 inhibitor, SB203580 $(1 \mu \mathrm{M} / \mathrm{ml})$ suppressed GM-CSF-induced surface expression of CD14 to basal level (Figure 7B). U0126 had no effect in the surface expression of CD14. We further assessed the phosphorylation of ERK $1 / 2$ and $\mathrm{p} 38$ by western blotting. GM-CSF increased the levels of phosphorylated ERK1/2 and p38, respectively, which peaked at 15 minutes (Figure 7C). Accordingly, U0126, SB203580, or $\mathrm{U} 0126+$ SB203580 pretreatment before GM-CSF priming decreased LPS-mediated production of IL- $1 \beta$, IL-6, TNF- $\alpha$ and NO in microglia (Figure 8). Taken together, these data indicate that GM-CSF increases TLR4 surface expression via ERK1/2 and that of CD14 via p38.

\section{Discussion}

Here we have shown that GM-CSFR complex is expressed by microglia but not astrocytes and cortical neurons in the

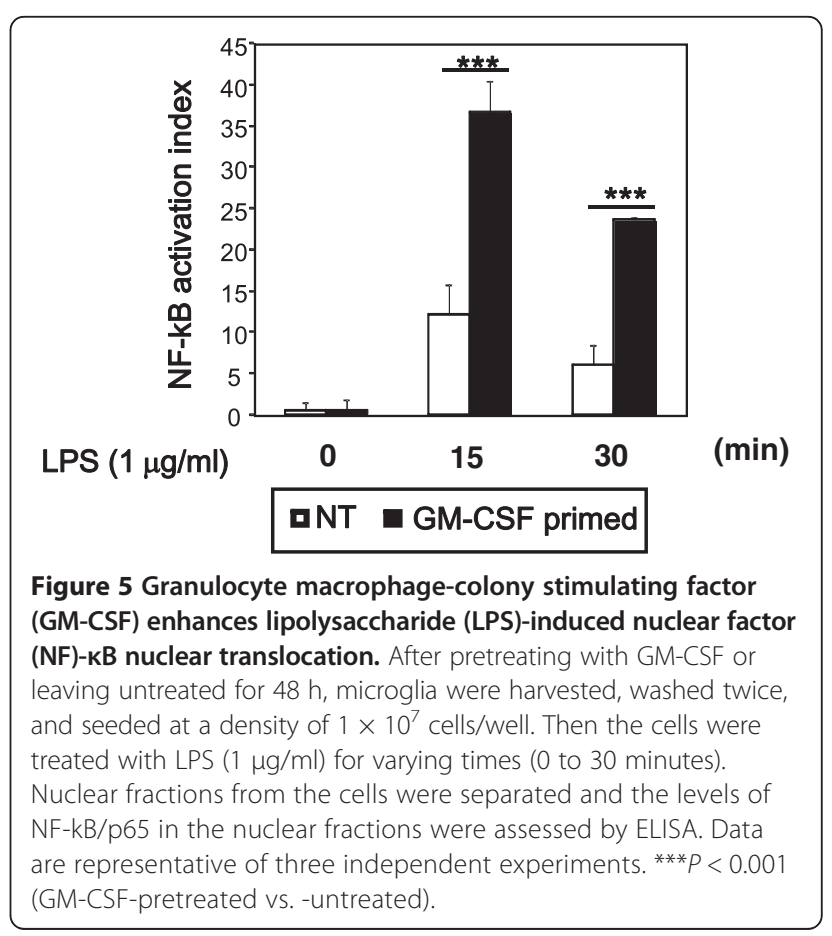




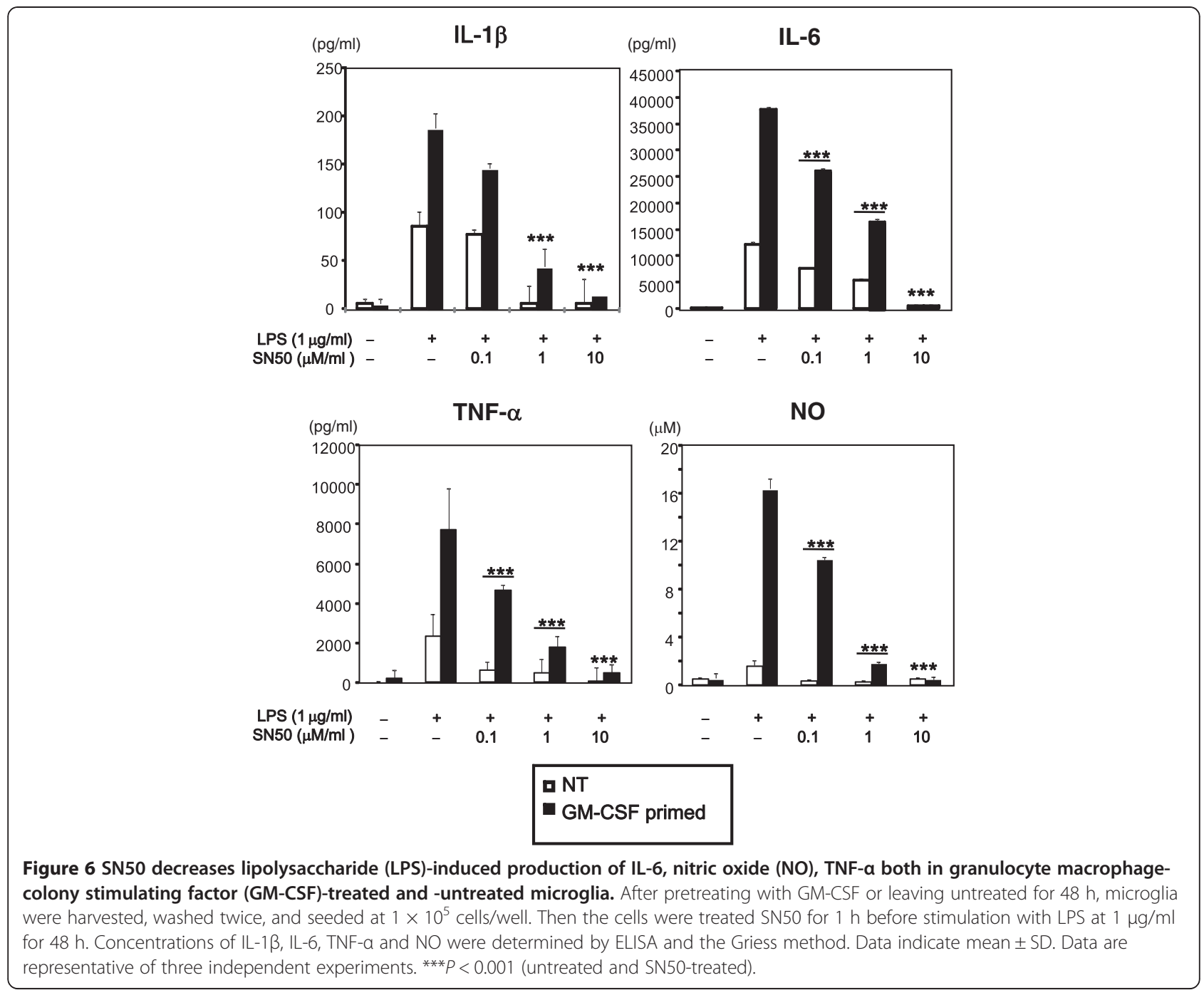

CNS, as no immunoreactivity for GM-CSFR $\alpha$, which is required for binding GM-CSF, was found in GFAPpositive astrocytes or in MAP2-positive cortical neurons. In contrast to our finding, previous reports suggested expression of GM-CSFR $\alpha$ in astrocytes and neurons [33-35]. However, we could not find any staining in neurons and astrocytes. However, we cannot rule out the possibility of regional- or maturation-specific expression of GM-CSFR $\alpha$ in neurons, as described previously, and upregulation of GM-CSFR $\alpha$ in activated astrocytes under host-specific conditions.

We showed that GM-CSF increased both mRNA and surface expression of TLR4 and CD14 via activation of ERK1/2 and p38, respectively, and pretreatment with U0126, SB203580, or both, indeed inhibit LPS-induced production of proinflammatory mediators in the microglia incubated with GM-CSF. In the peripheral immune system, it has been shown that peritoneal macrophages from GM-CSF knockout mice are hyposensitive to LPS
[36], and GM-CSF is required for the expression of TLR4 and CD14 in alveolar macrophages [37]. Similarly, we showed that GM-CSF enhances LPS-induced production of inflammatory mediators by promoting TLR4 expression, which is consistent with a previous report showing that the magnitude of LPS response correlates with total TLR4 expression levels [38]. Moreover, Helicobacter pylori LPS upregulate TLR4 expression via ERK1/2 in the gastric epithelial cell line, MKN28, and GM-CSF reportedly upregulate TLR4 expression via ERK1/2 in human blood monocytes respectively $[39,40]$. GM-CSF is reported to be required for CD14 expression in murine alveolar macrophages and human myeloid leukemia cells, whereas in human blood monocytes GM-CSF has been found to have no effect in CD14 expression [37,40,41]. Similarly, in the human monocytic cell line U937, both p38 and ERK1/2 activation have been shown to increase CD14 expression [42]. However, in our experiment, inhibiting p38 but not ERK1/2 decreased the surface expression of 

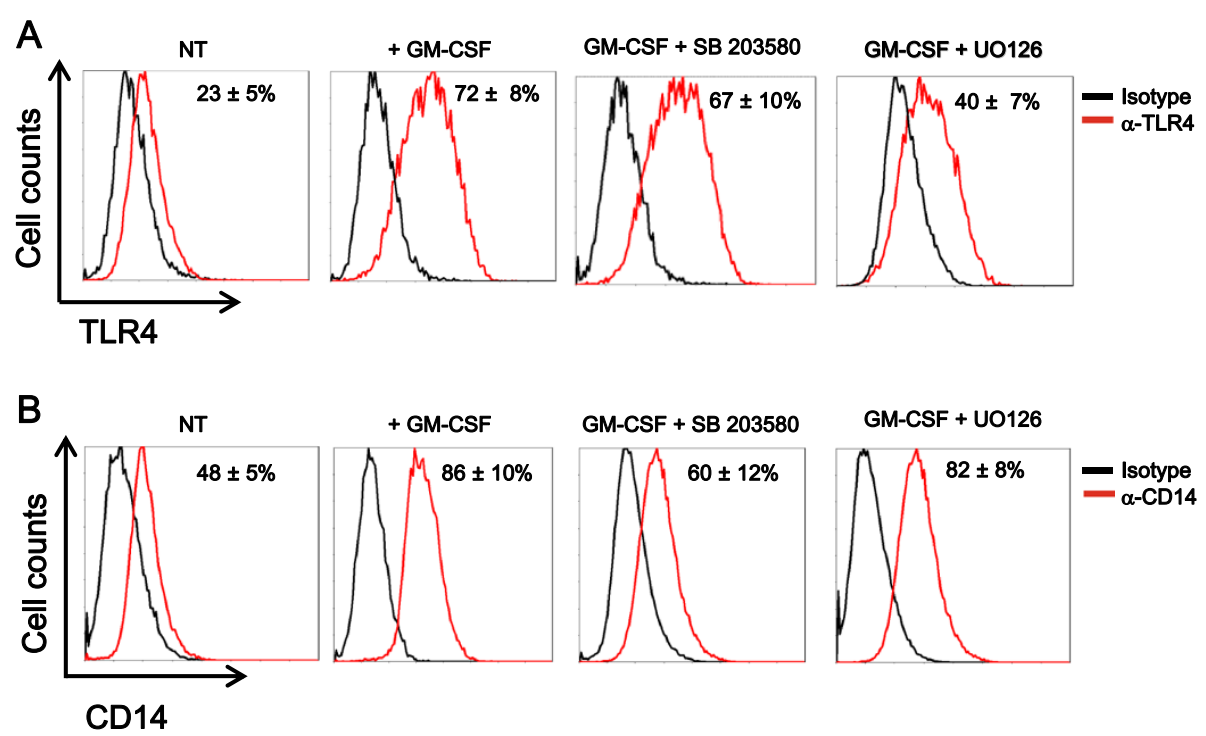

C

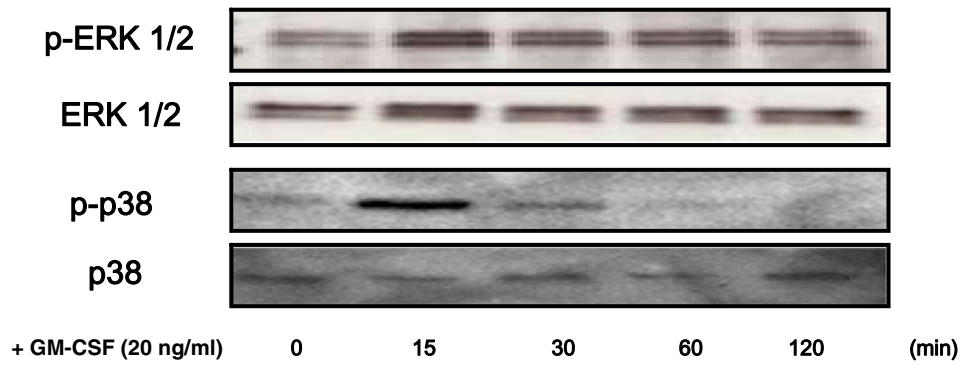

Figure 7 Granulocyte macrophage-colony stimulating factor (GM-CSF) upregulates toll-like receptor (TLR) 4 and CD14 expression via extracellular signal-regulated kinase (ERK) 1/2 and p38, respectively. (A, B) Microglia were pretreated with U0126 or SB 203580 for $1 \mathrm{~h}$ before stimulation with $20 \mathrm{ng} / \mathrm{ml} \mathrm{GM}$-CSF for $48 \mathrm{~h}$. Surface expression levels of TLR4 were assessed by flow cytometry (FCM) (A). Data indicate mean \pm SD of three independent experiments; $P<0.001$ (between GM-CSF and GM-CSF + U0126), $P<0.05$ (between NT and GM-CSF + U0126). Surface expression levels of CD14 were assessed by FCM (B). Data indicate mean \pm SD of three independent experiments; $P<0.001$ (between GM-CSF and GM-CSF + SB 203580); P > 0.05 (between NT and GM-CSF + SB 203580). (C) Microglia were treated with $20 \mathrm{ng} / \mathrm{ml}$ GM-CSF. Then cells were lysed and total cell lysates were analyzed by western blotting for p-ERK1/2, ERK1/2, p-p38, and p38. Data are representative of two independent experiments.

CD14. Thus, CD14 may be differentially regulated in tissue-resident monocyte/macrophage cell-like microglia, alveolar macrophage and circulating monocytes.

TLR4 is required for the initiation of innate immune responses to LPS $[5,6]$. CD14 is a key LPS co-receptor, pivotal in the initial binding of LPS and transfer of LPS to MD2/TLR4 complex to initiate signal cascades [43-46]. In addition to LPS, various endogenous molecules such as HMGB1 and HSP60, which are released from dying cells, and misfolded proteins like mutant SOD1 and fibriller $A \beta$, as well as fibronection, have been shown to bind to TLR4 and CD14 [7,11,47-50]. Surface expression of TLR4 and CD14 in microglia has been shown to be elevated in various neurological disorders like ALS and $\mathrm{AD}[12,51]$. Indeed, chronic activation of TLR4 and CD14 by LPS has been shown to exacerbate disease in the mouse model of ALS [52]. It has also been shown that extracellular mSOD1 interacts with CD14 in microglia, which then associates with TLR2 and TLR4 activating the proinflammatory cascade [11]. Similarly, $A \beta$ has been shown to bind both TLR4 and CD14 and induce inflammation [7-10]. Thus, GM-CSF may function to exacerbate ALS and AD by increasing TLR4 and CD14 expression in microglia. Supporting this hypothesis, GM-CSF knockout mice have been reported to have delayed onset and increased life span in the mouse model of ALS [53]. In addition, blocking GM-CSF with anti-GMCSF antibodies reportedly decreased microglial activation in the mouse model of $\mathrm{AD}[25,54]$. However, there are several conflicting reports. GM-CSF is reported to be beneficial in the mouse model of Parkinson's disease and in stroke $[55,56]$. Thus, it is possible that GM-CSF may have both beneficial and detrimental effects, depending on the disease stages or pathogenesis. Further studies are 

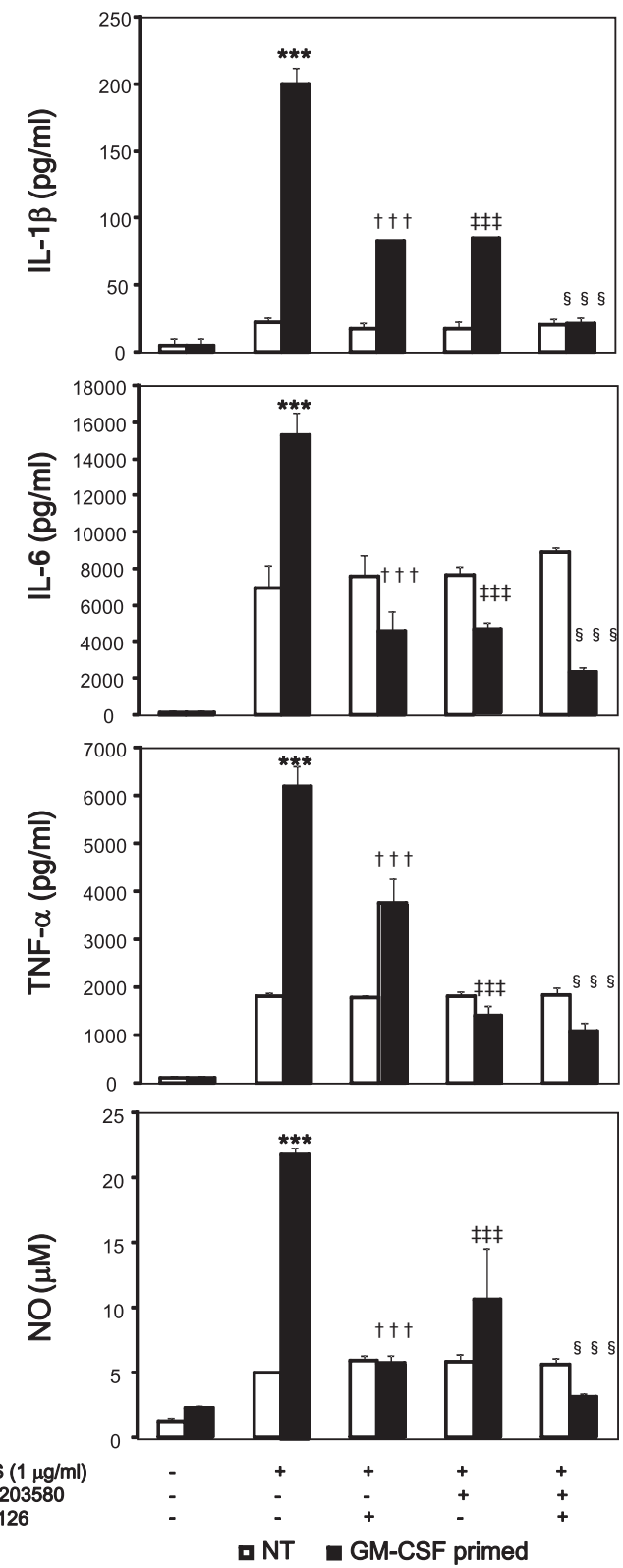

Figure 8 Inhibition of extracellular signal-regulated kinase (ERK) $1 / 2$, p38 decreases lipopolysaccharide (LPS)-induced production of IL-1 $\beta$, IL-6, TNF- $\alpha$ and nitric oxide (NO) in granulocyte macrophagecolony stimulating factor (GM-CSF)-treated microglia. Microglia were pretreated with U0126, SB 203580, or both, for $1 \mathrm{~h}$ and stimulated with GM-CSF $(20 \mathrm{ng} / \mathrm{ml})$ or left untreated for $48 \mathrm{~h}$. Then the cells were harvested, washed twice, and seeded at a density of $1 \times 10^{5}$ cells/well in 24-well plates. Cells were further stimulated with LPS $(1 \mu \mathrm{g} / \mathrm{ml})$ for $48 \mathrm{~h}$. Concentrations of IL-1 $\beta$, IL-6, TNF- $a$ and NO were determined by ELISA and the Griess method respectively. Data indicate mean \pm SD. Data are representative of two independent experiments. ${ }^{* * *} P<0.001$ (between GM-CSF-primed and -unprimed), ${ }^{++\dagger} P<0.001$ (between GM-CSF-primed and SB 203580-pretreated), 执 $P<0.001$ (between GM-CSF-primed and U0126-pretreated), ${ }^{\$ \S \S} P<0.001$ (between GM-CSF-primed and SB $203580+$ U0126-pretreated) needed to examine the role of GM-CSF in various neurological disorders.

\section{Conclusions}

GM-CSF increases surface expression of TLR4 and CD14 in microglia, which is mediated by ERK1/2 and p38, respectively. Accordingly, GM-CSF upregulates LPS-induced IL-1 $\beta$, IL-6, TNF- $\alpha$, and NO production and may promote neuroinflammation.

\section{Abbreviations}

AD: Alzheimer's disease; ALS: Amyotrophic lateral sclerosis; ANOVA: One-way analysis of variance; $\beta \mathrm{C}$ : Common $\beta$ chain; CNS: Central nervous system; ERK: Extracellular signal-regulated kinase; FACS: Fluorescence-activated cell sorter; FCM: Flow cytometry; GFAP: Glial fibrillary acidic protein; GMCSF: Granulocyte macrophage-colony stimulating factor; IL: Interleukin; NOS2: Nitric oxide synthase 2; JAK: Janus kinase; LPS: Lipopolysaccharide; MAPK: Mitogen-activated protein kinase; mSOD: Mutations in superoxide dismutase; MS: Multiple sclerosis; NF-kB: Nuclear factor-KB; NO: Nitric oxide; PBS: Phosphate-buffered saline; PI3K: Phosphatidylinositol-3 kinase; PCR: Polymerase chain reaction; TLR: Toll-like receptor; TNF: Tumor necrosis factor.

\section{Competing interests}

The authors declare that they have no competing interests.

\section{Authors' contributions}

BP performed the experiments and helped draft the manuscript. YD, JK, and NM performed the cell culture and were involved in the conception of study. TM and TH helped with the preparation of the manuscript. YS was involved in the conception and design of the study and helped draft the manuscript. AS was involved in the conception and design of the study and helped draft the manuscript. All authors read and approved the final manuscript.

\section{Acknowledgements}

This work was supported by the Advanced research for medical products Mining Programme of the National Institute of Biomedical Innovation (NIBIO); a Grant-in-Aid for the global COE program from the Ministry of Education, Culture, Sports, Science and Technology of Japan, and a Research Grant on Intractable Diseases (Neuroimmunological Diseases) from the Ministry of Health, Labour and Welfare of Japan.

\section{Author details}

${ }^{1}$ Department of Neuroimmunology, Research Institute of Environmental Medicine, Nagoya University, Furo-cho, Chikusa-ku, Nagoya 464-8601, Japan. 2Department of Anatomy, School of Medicine, Keio University, Shinanomachi, Tokyo, Japan.

Received: 25 August 2012 Accepted: 26 November 2012 Published: 13 December 2012

\section{References}

1. Carpentier PA, Duncan DS, Miller SD: Glial toll-like receptor signaling in central nervous system infection and autoimmunity. Brain Behav Immun 2008, 22:140-147.

2. Rivest S: Molecular insights on the cerebral innate immune system. Brain Behav Immun 2003, 17:13-19.

3. Aravalli RN, Peterson PK, Lokensgard JR: Toll-like receptors in defense and damage of the central nervous system. J Neuroimmune Pharmacol 2007, 2:297-312.

4. Sawada M, Kondo N, Suzumura A, Marunouchi T: Production of tumor necrosis factor-alpha by microglia and astrocytes in culture. Brain Res 1989, 491:394-397.

5. Kawai T, Akira S: The role of pattern-recognition receptors in innate immunity: update on Toll-like receptors. Nat Immunol 2010, 11:373-384.

6. Kawai T, Akira S: Signaling to NF-kappaB by Toll-like receptors. Trends Mol Med 2007, 13:460-469. 
7. Tahara K, Kim HD, Jin JJ, Maxwell JA, Li L, Fukuchi K: Role of toll-like receptor signalling in Abeta uptake and clearance. Brain 2006, 129:3006-3019.

8. Jin JJ, Kim HD, Maxwell JA, Li L, Fukuchi K: Toll-like receptor 4-dependent upregulation of cytokines in a transgenic mouse model of Alzheimer's disease. J Neuroinflammation 2008, 5:23.

9. Reed-Geaghan EG, Reed QW, Cramer PE, Landreth GE: Deletion of CD14 attenuates Alzheimer's disease pathology by influencing the brain's inflammatory milieu. J Neurosci 2010, 30:15369-15373.

10. Reed-Geaghan EG, Savage JC, Hise AG, Landreth GE: CD14 and toll-like receptors 2 and 4 are required for fibrillar A\{beta\}-stimulated microglial activation. J Neurosci 2009, 29:11982-11992.

11. Zhao W, Beers DR, Henkel JS, Zhang W, Urushitani M, Julien JP, Appel SH: Extracellular mutant SOD1 induces microglial-mediated motoneuron injury. Glia 2010, 58:231-243.

12. Casula M, lyer AM, Spliet WG, Anink JJ, Steentjes K, Sta M, Troost D, Aronica E: Toll-like receptor signaling in amyotrophic lateral sclerosis spinal cord tissue. Neuroscience 2011, 179:233-243.

13. Broudy VC, Kaushansky K, Segal GM, Harlan JM, Adamson JW: Tumor necrosis factor type alpha stimulates human endothelial cells to produce granulocyte/macrophage colony-stimulating factor. Proc Natl Acad Sci U S A 1986, 83:7467-7471.

14. Ohno K, Suzumura A, Sawada M, Marunouchi T: Production of granulocyte/macrophage colony-stimulating factor by cultured astrocytes. Biochem Biophys Res Commun 1990, 169:719-724.

15. Ponomarev ED, Shriver LP, Maresz K, Pedras-Vasconcelos J, Verthelyi D, Dittel BN: GM-CSF production by autoreactive T cells is required for the activation of microglial cells and the onset of experimental autoimmune encephalomyelitis. J Immunol 2007, 178:39-48.

16. El-Behi M, Ciric B, Dai H, Yan Y, Cullimore M, Safavi F, Zhang GX, Dittel BN, Rostami A: The encephalitogenicity of $\mathrm{T}(\mathrm{H}) 17$ cells is dependent on IL-1and IL-23-induced production of the cytokine GM-CSF. Nat Immunol 2011, 12:568-575.

17. Codarri L, Gyulveszi G, Tosevski V, Hesske L, Fontana A, Magnenat L, Suter T, Becher B: RORgammat drives production of the cytokine GM-CSF in helper T cells, which is essential for the effector phase of autoimmune neuroinflammation. Nat Immunol 2011, 12:560-567.

18. Hayashida K, Kitamura T, Gorman DM, Arai K, Yokota T, Miyajima A: Molecular cloning of a second subunit of the receptor for human granulocyte-macrophage colony-stimulating factor (GM-CSF): reconstitution of a high-affinity GM-CSF receptor. Proc Natl Acad Sci USA 1990, 87:9655-9659.

19. Muto A, Watanabe S, Miyajima A, Yokota T, Arai K: The beta subunit of human granulocyte-macrophage colony-stimulating factor receptor forms a homodimer and is activated via association with the alpha subunit. J Exp Med 1996, 183:1911-1916.

20. Liva SM, Kahn MA, Dopp JM, de Vellis J: Signal transduction pathways induced by GM-CSF in microglia: significance in the control of proliferation. Glia 1999, 26:344-352.

21. Sato N, Sakamaki K, Terada N, Arai K, Miyajima A: Signal transduction by the high-affinity GM-CSF receptor: two distinct cytoplasmic regions of the common beta subunit responsible for different signaling. EMBO J 1993, 12:4181-4189.

22. Quelle FW, Sato N, Witthuhn BA, Inhorn RC, Eder M, Miyajima A, Griffin JD, Ihle JN: JAK2 associates with the beta c chain of the receptor for granulocyte-macrophage colony-stimulating factor, and its activation requires the membrane-proximal region. Mol Cell Biol 1994, 14:4335-4341.

23. Tarkowski E, Wallin A, Regland B, Blennow K, Tarkowski A: Local and systemic GM-CSF increase in Alzheimer's disease and vascular dementia. Acta Neurol Scand 2001, 103:166-174.

24. Mellergard J, Edstrom M, Vrethem M, Ernerudh J, Dahle C: Natalizumab treatment in multiple sclerosis: marked decline of chemokines and cytokines in cerebrospinal fluid. Mult Scler 2010, 16:208-217.

25. Manczak M, Mao P, Nakamura K, Bebbington C, Park B, Reddy PH: Neutralization of granulocyte macrophage colony-stimulating factor decreases amyloid beta 1-42 and suppresses microglial activity in a transgenic mouse model of Alzheimer's disease. Hum Mol Genet 2009, 18:3876-3893

26. Li H, Sonobe Y, Tabata H, Liang J, Jin S, Doi Y, Kawanokuchi J, Takeuchi H, Mizuno T, Suzumura A: Tumor necrosis factor-a promotes granulocytemacrophage colony-stimulating factor-stimulated microglia to differentiate into competent dendritic cell-like antigen-presenting cells. Clinical Exp Neuroimmunol 2011, 2:1-11.

27. Suzumura A, Sawada M, Marunouchi T: Selective induction of interleukin-6 in mouse microglia by granulocyte-macrophage colony-stimulating factor. Brain Res 1996, 713:192-198.

28. Mizuno T, Kurotani T, Komatsu Y, Kawanokuchi J, Kato H, Mitsuma N, Suzumura A: Neuroprotective role of phosphodiesterase inhibitor ibudilast on neuronal cell death induced by activated microglia. Neuropharmacology 2004, 46:404-411.

29. Zhou Y, Sonobe $Y$, Akahori T, Jin S, Kawanokuchi J, Noda M, Iwakura $Y$, Mizuno T, Suzumura A: IL-9 promotes Th17 cell migration into the central nervous system via CC chemokine ligand- 20 produced by astrocytes. J Immunol 2011, 186:4415-4421.

30. Sonobe Y, Li H, Jin S, Kishida S, Kadomatsu K, Takeuchi H, Mizuno T, Suzumura A: Midkine inhibits inducible regulatory $T$ cell differentiation by suppressing the development of tolerogenic dendritic cells. J Immunol 2012, 188:2602-2611.

31. Parajuli B, Sonobe Y, Kawanokuchi J, Doi Y, Noda M, Takeuchi H, Mizuno T, Suzumura A: Immunoglobulin G(1) immune complex upregulates interferon-gamma-induced nitric oxide production via ERK1/2 activation in murine microglia. J Neuroimmunol 2012, 244:57-62.

32. Mizuno T, Doi Y, Mizoguchi $H$, Jin S, Noda M, Sonobe $Y$, Takeuchi $H$, Suzumura A: Interleukin-34 selectively enhances the neuroprotective effects of microglia to attenuate oligomeric amyloid-beta neurotoxicity. Am J Pathol 2011, 179:2016-2027.

33. Schabitz WR, Kruger C, Pitzer C, Weber D, Laage R, Gassler N, Aronowski J, Mier W, Kirsch F, Dittgen T, Bach A, Sommer C, Schneider A: A neuroprotective function for the hematopoietic protein granulocytemacrophage colony stimulating factor (GM-CSF). J Cereb Blood Flow Metab 2008, 28:29-43.

34. Kruger C, Laage R, Pitzer C, Schabitz WR, Schneider A: The hematopoietic factor GM-CSF (granulocyte-macrophage colony-stimulating factor) promotes neuronal differentiation of adult neural stem cells in vitro. BMC Neurosci 2007, 8:88.

35. Reed JA, Clegg DJ, Smith KB, Tolod-Richer EG, Matter EK, Picard LS, Seeley RJ: GM-CSF action in the CNS decreases food intake and body weight. J Clin Invest 2005, 115:3035-3044.

36. Basu S, Dunn AR, Marino MW, Savoia H, Hodgson G, Lieschke GJ, Cebon J: Increased tolerance to endotoxin by granulocyte-macrophage colonystimulating factor-deficient mice. J Immunol 1997, 159:1412-1417.

37. Shibata Y, Berclaz PY, Chroneos ZC, Yoshida M, Whitsett JA, Trapnell BC: GM-CSF regulates alveolar macrophage differentiation and innate immunity in the lung through PU.1. Immunity 2001, 15:557-567.

38. Nomura F, Akashi S, Sakao Y, Sato S, Kawai T, Matsumoto M, Nakanishi K, Kimoto M, Miyake K, Takeda K, Akira S: Cutting edge: endotoxin tolerance in mouse peritoneal macrophages correlates with down-regulation of surface toll-like receptor 4 expression. J Immunol 2000, 164:3476-3479.

39. Yokota S, Okabayashi T, Rehli M, Fujii N, Amano K: Helicobacter pylori lipopolysaccharides upregulate toll-like receptor 4 expression and proliferation of gastric epithelial cells via the MEK1/2-ERK1/2 mitogenactivated protein kinase pathway. Infect Immun 2010, 78:468-476.

40. Lendemans S, Rani M, Selbach C, Kreuzfelder E, Schade FU, Flohe S: GM-CSF priming of human monocytes is dependent on ERK1/2 activation. J Endotoxin Res 2006, 12:10-20.

41. Akin C, Sonnenfeld G: Stimulation of granulocyte-macrophage colonystimulating factor (GM-CSF) production and its role as an autocrine inducer of CD14 upregulation in human myeloid leukemia cells. J Interferon Cytokine Res 1996, 16:479-486.

42. Nareika A, Im YB, Game BA, Slate EH, Sanders JJ, London SD, Lopes-Virella $M F$, Huang $Y$ : High glucose enhances lipopolysaccharide-stimulated CD14 expression in U937 mononuclear cells by increasing nuclear factor kappaB and AP-1 activities. J Endocrinol 2008, 196:45-55.

43. Wright SD, Ramos RA, Tobias PS, Ulevitch RJ, Mathison JC: CD14, a receptor for complexes of lipopolysaccharide (LPS) and LPS binding protein. Science 1990, 249:1431-1433.

44. Shin HJ, Lee H, Park JD, Hyun HC, Sohn HO, Lee DW, Kim YS: Kinetics of binding of LPS to recombinant CD14, TLR4, and MD-2 proteins. Mol Cells 2007, 24:119-124.

45. Regan T, Rossum D, Scheffel J, Kastriti ME, Revelo MH, Prinz M, Bruck W, Hanish UK: CD14 and TRIF govern distinct responsiveness and responses 
in mouse microglial TLR4 challenges by structural variants of LPS. Brain Behav Immun 2011, 25:957-970.

46. Liu Y, Walter S, Stagi M, Cherny D, Letiembre M, Schulz-Schaeffer W, Heine $H$, Penke B, Neumann H, Fassbender K: LPS receptor (CD14): a receptor for phagocytosis of Alzheimer's amyloid peptide. Brain 2005, 128:1778-1789.

47. Ohashi K, Burkart V, Flohe S, Kolb H: Cutting edge: heat shock protein 60 is a putative endogenous ligand of the toll-like receptor- 4 complex. J Immunol 2000, 164:558-561.

48. Park JS, Svetkauskaite D, He Q, Kim JY, Strassheim D, Ishizaka A, Abraham E: Involvement of toll-like receptors 2 and 4 in cellular activation by high mobility group box 1 protein. J Biol Chem 2004, 279:7370-7377.

49. Goos M, Lange P, Hanish UK, Prinz M, Scheffel J, Bregmann R, Ebsert S, Nau $R$ : Fibronectin is elevated in cerebrospinal fluid of patients suffering from bacterial meningitis and enhances inflammation caused by bacterial products in primary mouse microglial cell cultures. J Neurochem 2007, 102:2049-2060.

50. Bate C, Veerhuis R, Eikelenboom P, Williams A: Microglia kill amyloid-beta142 damaged neurons by a CD14-dependent process. Neuro Report 2004, 15:1427-1430.

51. Frank S, Copanaki E, Burbach GJ, Muller UC, Deller T: Differential regulation of Toll like receptor mRNAs in amyloid plague-associated brain tissue of aged APP23 transgenic mice. Neurosci Lett 2009, 453:41-44.

52. Nguyen MD, D'Aigle T, Gowing G, Julien JP, Rivest S: Exacerbation of motor neuron disease by chronic stimulation of innate immunity in a mouse model of amyotrophic lateral sclerosis. J Neurosci 2004, 24:1340-1349.

53. Turner BJ, Talbot K: Transgenics, toxicity and therapeutics in rodent models of mutant SOD1-mediated familial ALS. Prog Neurobiol 2008, 85:94-134.

54. Reddy PH, Manczak M, Zhao W, Nakamura K, Bebbington C, Yarranton G, Mao P: Granulocyte-macrophage colony-stimulating factor antibody suppresses microglial activity: implications for anti-inflammatory effects in Alzheimer's disease and multiple sclerosis. J Neurochem 2009, 111:1514-1528.

55. Mangano EN, Peters S, Litteljohn D, So R, Bethune C, Bobyn J, Clarke M, Hayley S: Granulocyte macrophage-colony stimulating factor protects against substantia nigra dopaminergic cell loss in an environmental toxin model of Parkinson's disease. Neurobiol Dis 2011, 43:99-112.

56. Kong T, Choi JK, Park H, Choi BH, Snyder BJ, Bukhari S, Kim NK, Huang X, Park SR, Park HC, Ha Y: Reduction in programmed cell death and improvement in functional outcome of transient focal cerebral ischemia after administration of granulocyte-macrophage colony-stimulating factor in rats. Laboratory investigation. J Neurosurg 2009, 111:155-163.

doi:10.1186/1742-2094-9-268

Cite this article as: Parajuli et al.: GM-CSF increases LPS-induced production of proinflammatory mediators via upregulation of TLR4 and CD14 in murine microglia. Journal of Neuroinflammation 2012 9:268.

\section{Submit your next manuscript to BioMed Central and take full advantage of:}

- Convenient online submission

- Thorough peer review

- No space constraints or color figure charges

- Immediate publication on acceptance

- Inclusion in PubMed, CAS, Scopus and Google Scholar

- Research which is freely available for redistribution 